VICTORIA EUGENIA PETERS RADA

INSTITUCIÓN UNIVERSITARIA

POLITÉCNICO GRANCOLOMBIANO

BOGOTÁ, COLOMBIA

VPETERSR@POLIGRAN.EDU.CO

MILENA TRUJILLO ACOSTA

LCI, LASALLE COLLEGE INTERNATIONAL

BOGOTÁ, COLOMBIA

MILENATRUJILLOA@YAHOO.ES

1. Dispositivo: "un conjunto heterogéneo que abarca los discursos, instituciones, leyes, medidas administrativas, afirmaciones científicas, enseñanzas filosóficas, (...) lo que se dice y lo que no se dice (...)" (Jâger, 2003, pp. 119-120).

Financiamiento:

Institución Universitaria Politécnico

Grancolombiano, Gruplac CEC, linea Imagen,

Visualidad y Cultura, convocatoria 2018.

Fecha de recepción: 25/03/2019

Fecha de aceptación: 23/05/2019

Cómo citar: Peters Rada, V. y Trujillo Acosta, M

(2019) Publicaciones infantiles y su carga

ideológica. República Liberal de Colombia

(1933-1938)

RChD: creación y pensamiento, 4(6), 1-12

DOI: 10.5354/0719-837X.2019.52613

Revista Chilena de Diseño

RChD: creación y pensamiento

Universidad de Chile

2019, 4(6)

http://rchd.uchile.cl

\section{Publicaciones infantiles y su carga ideológica. República Liberal de Colombia (1933-1938)}

\author{
Children's Publications and their Ideological Load. \\ Liberal Republic of Colombia (1933-1938)
}

Resumen. En la década de los treinta, el gobierno liberal y la iglesia, de filiación conservadora, se disputaban el control en la formación de los ciudadanos. En la búsqueda de encontrar formas de influir, variar el ordenamiento social y transformar la realidad, uno y otra instrumentalizaron la educación por ser un medio apropiado para modelar el pensamiento desde la infancia. Chanchito, revista ilustrada para niños (1933-1934), expuso el ideario conservador y Rin Rin, revista infantil (1935-1939) junto con El país de Lilac (1938), libro de cuentos para niños, sirvieron de soporte a las ideologías liberales modernizadoras. El propósito de las publicaciones consistió en influir en la formación ciudadana desde la infancia y para la construcción del rol social del niño; cada una supo responder a propósitos instrumentalistas del discurso promovido por sus impulsores ideológicos. Desde la perspectiva de S. Jäger (2003), las tres publicaciones adquirieron el carácter de dispositivo'. Palabras clave: formación ciudadana, ideología bipartidista, libros infantiles, luchas bipartidistas, publicaciones colombianas.

Abstract. In the thirties, the liberal government and the church, of conservative filiation, disputed control in the formation of citizens. In the quest to find ways to influence, vary the social order and transform reality, both instrumentalized education as an appropriate means to model thought from childhood. Chanchito, an illustrated magazine for children (1933-1934), exhibited the Conservative Idea and Rin Rin, a children's magazine (1935-1939) together with El país de Lilac (1938), a children's storybook, supported modernizing liberal ideologies. The publications were produced with the purpose of influencing the civic formation from childhood and for the construction of the social role of the child; each knew how to respond to instrumentalist purposes of the discourse promoted by its ideological drivers. From the perspective of S. Jäger (2003), the three publications acquired the character of a device.

Keywords: Bipartisan Ideology, Bipartisan Struggles, Civic education, Children's books, Colombian Publications. 
Figura 1. Esquema del dispositivo. Fuente: elaboración de las autoras.

\section{Dispositivo}

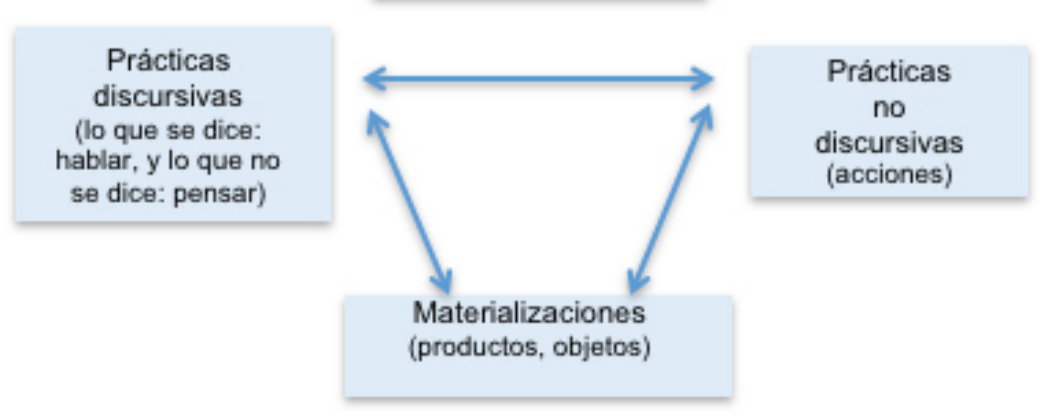

\section{Introducción}

Chanchito fue dirigida por Víctor E. Caro, heredero de la ideología tradicionalista y católica; Rin Rin fue parte de los "Órganos de Expresión del Ministerio de Educación Nacional de Colombia” por considerársele un instrumento cultural de la República (López de Mesa, 1935), y circuló en las escuelas públicas primarias. En cuanto a El país de Lilac era el título bajo el cual se publicaron doce cuentos para niños, escritos por Oswaldo Díaz Díaz, e ilustrados por Sergio Trujillo Magnenat, y editados también por el Ministerio de Educación Nacional como parte de la colección de Literatura Colombiana.

En conjunto, el corpus a analizar recoge tres publicaciones infantiles producidas entre 1933 y 1938 , periodo que se circunscribe dentro de lo que fue la Republica Liberal (1930 - 1946). Una época en la que se radicalizó el uso de la educación como mecanismo ideológico y se quiso moldear la realidad social asignándole al niño, a la familia o al Estado un rol en la construcción de ciudadanía. En este artículo se indaga sobre los agentes políticos encargados de instruir a la infancia y moldear el rol infantil acorde con las ideologías instructoras. Este texto da continuidad al artículo publicado bajo el título "Rin Rin. Revista Infantil"... en la revista Análisis (Trujillo Acosta \& Peters Rada, 2018)

\section{Metodología / Teoría}

La naturaleza del corpus a estudiar, desde un enfoque cualitativo, condujo a la adopción del Análisis Crítico del Discurso (ACD) desarrollado por S. Jäger (2003): este es el principal referente teórico, analítico y metodológico de la investigación. Las publicaciones, objeto de análisis, se comprenden como medios discursivos a través de los cuales "los discursos ejercen el poder porque transportan un saber con el que se nutre la consciencia colectiva e individual" (p. 69) y funcionan como dispositivos, ya que trasportan un "conocimiento emergente constitutivo (para) la acción individual y colectiva, así como el fundamento de la acción formativa que moldea la realidad".

Jäger propone visualizar el concepto de dispositivo como un esquema del que hacen tres "puntos centrales de tránsito", que van rotando en el transcurso del tiempo (historia). La Figura 1, da cuenta del esquema.

1. Las prácticas discursivas: hablar y pensar sobre la base del conocimiento.

2. Las prácticas no discursivas: actuar sobre la base del conocimiento.

3. Las manifestaciones y las materializaciones del conocimiento.

El término conocimiento incluye emociones, sentimientos, afectos, entre otros. 
Desde esta perspectiva, las tres publicaciones infantiles se configuran como medios discursivos y como dispositivos. Jäger (2003) siguiendo la vertiente de Foucault, adhiere a que el conocimiento es la base de la acción formativa que configura la realidad, y esta es desplegada en prácticas discursivas y no discursivas y mediante manifestaciones y materializaciones. Tanto para Foucault como para Jäger, el dispositivo es la interacción entre estos diferentes elementos. Por ello, los impresos referenciados se analizan desde una doble perspectiva: como elementos de los dispositivos de poder de la disputa bipartidista y, como dispositivos, en sí mismos, al servicio de un tipo de ideología.

En términos metodológicos, el análisis comparativo entre las tres publicaciones implicó la consulta de archivos impresos, documentos históricos y gráficos de la época. En las publicaciones se analizaron los diversos planos discursivos en textos e imágenes al tiempo que se confrontaron con el contexto, las leyes, la educación y la historia de la época para encontrar la concordancia entre los impresos y su función de dispositivo.

Este articulo da cuenta de un avance de los resultados obtenidos en el marco de una investigación interinstitucional emprendida con financiación de la Institución Universitaria Politécnico Grancolombiano, Gruplac CEC Imagen, Visualidad y Cultura, convocatoria 2018 y por el grupo de investigación de LCl, Bogotá. El grupo de estudio tiene por objetivo la recuperación y la investigación patrimonial e histórica del archivo del artista multidisciplinar Sergio Trujillo Magnenat (1930-1950) y de la revista Chanchito.

\section{Discusión}

Las tres publicaciones contienen, textual y visualmente, discursos intencio-

nados alejados de espontáneas dinámicas sociales. Detrás de los personajes literarios encarnados en Chanchito y de las imágenes y los textos de Rin Rin y EI país de Lilac estuvieron presentes -a manera de dispositivo- las ideologías que se requería fueran aceptadas y compartidas por los pequeños ciudadanos. Chanchito fue fundada por Víctor Caro, circularon ininterrumpidamente sesenta y tres números entre 1933 y 1934, y se distribuyó entre la población infantil urbana. La publicación tuvo un enfoque instructivo y fines recreativos, pretendía nutrir "el alma nacional infantil" ante la ausencia de materiales para la infancia (Caro, 1933, p. 3). Rin Rin, en cambio, se produjo de manera irregular, se distribuyó entre los niños de la escuela primaria pública y obligatoria, y apenas si llegó a la edición número 13 a pesar de haber circulado entre 1936 y 1939.

Rin Rin y El país de Lilac representan dispositivos del proyecto liberal la “Revolución en Marcha”, primer mandato de Alfonso López Pumarejo. Rin Rin suplía la carencia de textos escolares para la básica primaria. El gobierno consciente del poder de los medios los utilizó para promover un nuevo orden social y una ciudadanía con noción de identidad nacional territorial. Al nacionalizarse, la educación (Figura I) fue necesaria la producción local de publicaciones que pudieran guiar a la infancia hacia una economía nacional y productivista (Figura 1).

El país de Lilac, autodenominado "el primer libro de cuentos imaginado y escrito especialmente para la infancia colombiana” (Díaz Díaz, 1938, p. 1) tenía como propósito contribuir a la formación de una ciudadanía, alejada de la tradicional enseñanza católica a la que se le consideraba represiva; más bien propugnaba porque el niño dejara de ser un sujeto pasivo y de mente abierta a la cultura moderna. 
2. Rafael Núñez, político liberal converso hacia

el partido conservador. Propuso como factor de progreso y de unidad nacional el fortalecimiento del Estado central y a la fe de la religión católica para la cohesión social y la regeneración individual (Arias, 2003).

\section{Contexto}

En la medida en que el Estado y la Iglesia se disputaban el control de la educación, la influencia de una u otra ideología determinó los contenidos textuales y visuales expuestos tanto en Rin Rin como en El país de Lilac. Un claro ejemplo de ello lo constituye el hecho de que bajo la presidencia de Alfonso López Pumarejo (1934-1938) se hubieran llevado a cabo acciones legislativas con las que se puso fin a los privilegios de la Iglesia en materia educativa, estableciendo un nuevo orden que aseguraba el progreso nacional (Cajas, 2013). Desde la década de 1880 hasta los años 30 del siglo XX, el poder hegemónico de las oligarquías tradicionalistas católicas y de la iglesia misma, al amparo del partido conservador, mantuvieron la idea que la fuerza nacional radicaba en el Estado central y que la fuerza cohesionadora de la identidad y del espíritu nacional estaba en la vinculación Estado-Iglesia y en la fe católica (Arias, 2003). En Chanchito se perpetuó el tradicionalismo y el catolicismo fiel a la ideología conservadora, Rin Rin y El país de Lilac, por su parte, difundieron una cultura laica como expresión de modernidad.

Resulta comprensible que el espacio protagónico en la disputa bipartidista buscara el control del ordenamiento social. La infancia, periodo más relevante del desarrollo del sujeto, se convirtió en la etapa a intervenir si se quería construir una nueva ciudadanía y lograr la reconfiguración social. Desde esta perspectiva, la educación pasa a ser el instrumento que, en una u otras manos, se utilizó para difundir la ideología y mantener el control sobre la organización social.

\section{Chanchito, revista heredera de la "Hegemonía Conservadora"}

Chanchito es herencia de la "Hegemonía Conservadora" instalada en Colombia entre 1886 y 1930. Dicho periodo se inicia con la Constitución de 1886, carta redactada por Rafael Núñez ${ }^{2}$ y Miguel Antonio Caro. Núñez se empeña en unificar el Estado, lograr armonía social y el desarrollo nacional (Tirado, 1995). Por su parte, Miguel Antonio Caro, dirigente del partido conservador y político influyente del siglo XIX, dio continuidad a los ideales de Rafael Núñez $y$, a la vez, se hizo defensor del legado hispanista como base para la configuración de la identidad nacional. Sus principios basados en la tradición, la religión católica y en un Estado centralista y autoritario fueron ideados para preservar el orden y la cohesión social. Estos principios que durante la Hegemonía Conservadora rechazaron de lleno la Revolución mexicana y bolchevique y sus posibles influencias en Colombia (Cajas, 2019).

Como heredera de la Constitución de 1886, Chanchito trasmite el ideal de construcción nacional bajo la égida de la Iglesia católica, noción que había arraigado el binomio de la identidad colombiana con el ser católico. Así quedó en la Constitución de 1886.

La Constitución, invocada en nombre de Dios, "fuente suprema de toda autoridad" (Preámbulo), reconoce que "la Religión Católica, Apostólica y Romana, es de la Nación", por los que "los Poderes públicos la protegerán y harán que sea respetada como esencial elemento del orden social" (...) (Artículo 38) (...) En materia educativa, se establece que "La educación pública será organizada y dirigida en concordancia con la Religión Católica" (artículo 41) (...). (Arias, 2003, pp. 51-52)

El Concordato firmado en 1887 entregó el control ideológico de la educación a la Iglesia y, desde entonces, el moldeamiento de los ciudadanos productivos 
era el de cristianos devotos y servidores del Estado (Herrera, 2019).

Allí queda constancia también de la importancia del clero en materia educativa. El artículo 12 reconocía el papel docente del clero en universidades, colegios, escuelas, centros educativos y de instrucción pública para ser organizados conforme a los dogmas y la moral de la religión católica. Los obispos diocesanos serían inspectores, estarían encargados de la selección de textos de religión y moral para la enseñanza nacional oficial. Así mismo, en el artículo 13 se establece la imposibilidad de enseñar en los planteles educativos asignaturas que propagaran ideas contrarias al dogma católico y que se pronunciaran en contra de la Iglesia (Arias, 2003).

Los ideales tradicionalistas de la Constitución de 1886 fueron ratificados en los artículos 48 y 53 del Decreto 491 de 1904, por el cual se reglamentó la Ley 89 de 1903 sobre Instrucción Pública. En ellos se reforzó la práctica de los deberes de los alumnos para con Dios, para consigo mismo, para con sus padres, sus superiores y para con la patria. A partir de estas disposiciones, se diferenció el pensum educativo para niños y para niñas y las materias para cada nivel (Diario Oficial de la Nación Número 12,122, jueves 14 de julio de 1904).

\section{Los roles de género}

En Chanchito la tradición se perpetuaba mediante la asignación de roles por género y principios de autoridad; hace de la familia la institución educadora y núcleo referencial de los roles a imitar y a partir de ellos se formaría el niño como trabajador del mañana y de la niña como ama de casa. La coeducación propuesta por los liberales fue rechazada por el partido conservador y la Iglesia, previendo los terribles efectos morales de la educación mixta.

En la Ley 39 de 1903 ya se hacía énfasis en una formación productivista y práctica, orientada hacia la industria, el comercio o la agricultura y destinada especialmente a la formación ciudadana de los niños. En Chanchito correspondía a los padres y abuelos ocuparse de los pasatiempos de los niños mientras que las madres los apoyaban en su iniciación religiosa, e involucraban en la búsqueda de ingredientes para la cocción de alimentos o en la aplicación de remedios caseros. Las amas de casa tenían, entre sus obligaciones, la enseñanza de la doctrina cristiana a los niños y la servidumbre (Londoño, 2005). Los manuales de Urbanidad, tanto de Manuel Antonio Carreño como el de Lucio Milcíades Chávez, que circularon en las escuelas, hacían énfasis en la importancia de la educación y rol de las niñas. Por su parte, las páginas de Chanchito también dan cuenta de dicha orientación: temas como el orden, el aseo, la forma de vestir o la economía doméstica eran asunto de mujeres y había que aprenderlo desde la niñez.

En la cubierta del número 14 y en varias páginas interiores se descubren imágenes en las que se muestran las diferencias entre uno y otro rol. Ellas aparecen con vestidos largos y recatados y a su lado están los niños. Dichas imágenes se combinan con narraciones locales, como Pastorcita de Rafael Pombo, relatos que contrastan con traducciones de príncipes y princesas europeos (Figura 2).

\section{Chanchito: el rol del niño(a) orientado(a)}

Acorde con los principios centralistas y autoritarios del partido conservador, en Chanchito los sujetos discursivos fueron construidos atendiendo principios de mando. En la publicación cada uno adquirió un rol discursivo, en el que se delimitaba quien ocupaba el rol de orientador y quien el rol de ser orientado. 

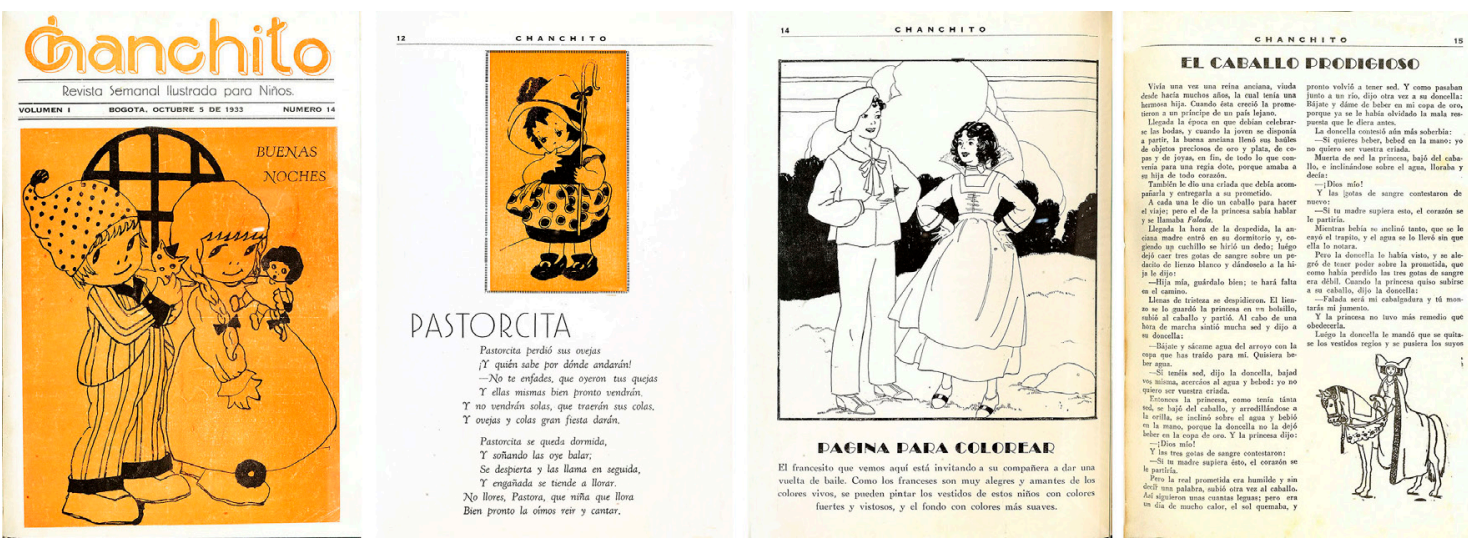

Figura 2. Chanchito, portada y páginas interiores.

3. Ver en Caro. (1933). Número 1, pág. 3; Caro. (1933). Número 17, pág. 4; Caro. (1934). Número 47, pág. 3; Caro. (1934). Número 49, pág. 4.
Esta delimitación expuso el deber que tenían los sujetos orientados (niños, niñas y alumnos) frente a las imposiciones de sus orientadores (padres, maestros, editores y Estado).

En la sección editorial de Chanchito, escrita por Víctor E. Caro, se infiere el discurso como una red, un dispositivo mediado por el afecto; quedando claro ¿quiénes eran los que instruían? y ¿quiénes los instruidos? En la editorial de la revista 4l, se alude a “Una araña”, relata la historia de la araña Epeira, texto del viejo Fabre que cuenta cómo la araña pasa toda la noche fabricando su maravillosa tela y espera a que caiga en la pegajosa red algún insecto. Esto se podría equiparar con lo que le sucede al director de la revista quien pretende tejer una red, "un hilo invisible que va del centro de la revista a mi corazón" para cazar a los suscriptores de Chanchito. Así queda en evidencia el peso que puede tener el discurso textual como vehículo de formación ciudadana. En otras secciones de la revista, se puede apreciar cómo Víctor E. Caro se dirigía a sus lectores como lectorcitos, chanchinómanos o pequeñuelos, expresiones que subalternizaron al niño y lo mantuvieron en su rol de orientado3. En lo educativo, a los niños se les habla de enmendar sus faltas y ser indulgentes con los defectos de los otros; también de formar un carácter fuerte para lo cual era necesario que siempre perseveraran en aquello que quisieran alcanzar y que no se dejaran vencer ni por amenazas ni por temores. De esta manera, se configura la virtud que representa al ciudadano bueno, limpio y obediente, tal y como se muestra en "La historia del tejón bondadoso" (Figura 3), relato que refiere cómo un tejón encontró y protegió a un niño de siete años, perdido en las praderas por más de dos semanas [...]. El relato reafirma a la literatura como un escenario proclive para ejemplificar buenas prácticas (Ospina, 2017). Caro dejó entrever, en la publicación, el rol social del niño como un adulto incompleto pero obediente y que adopta las prácticas del padre para reafirmar al propio padre. De esta forma, Víctor E. Caro, en tanto editor de la revista, se convertía en un protopadre, en el dueño de la familia, regentor de todas las relaciones que se dieron en el dispositivo y cuyo fin era cuidar los antiguos valores del orden social.

La revista no desaprovecha texto ni imagen para ejemplificar el rol del niño en calidad de sujeto heredero de las prácticas familiares. En la Figura 4, el texto “¿Fumamos?" alude a la práctica de fumar como un conocimiento que se trasmite de generación en generación. El lenguaje sutil y poder de la imagen lleva a que el niño asuma como normal Ahora comprendo por qué fuma 


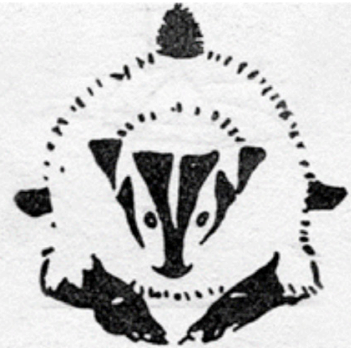

sus rasgos esenciales es verdad el relato, y asi lo afirmo yo gustoso, porque quiero que comprendáis la bondadosa disposición de ese recio, inofensivo y noble animal que se planta en los montículos bajos de las praderas, ya que estoy seguro de que os uniréis a mí para quererlo y para procurar salvar a su raza del exterminio.

papá, expresión donde la voz infantil se adueña del discurso y se apropia de su deseo de imitar al padre y de establecer el vínculo padre-hijo. El aviso incita a ambos a compartir un conocimiento, en este caso fumar, lo que es tan válido como compartir la experiencia de leer juntos. Por lo tanto, el rol del niño en Chanchito es un reflejo del adulto inacabado que replica las prácticas del padre, del profesor y de la madre.

\section{La familia Chanchito, vigilante de la tradición}

En el momento en que la revista Chanchito se publicó, la educación se regía por el Decreto 491 de 1904, que en su artículo 49 aludía a lo conveniente que resultaba la asociación del buen régimen de la escuela con la cultura moral guiada por las virtudes del Instructor; así, el maestro pasaba a encarnar las condiciones de un buen padre de familia y por lo tanto procuraría enseñar de manera similar a como se hacía en el hogar doméstico. Al mismo tiempo se incorporaba a la familia en la formación de los niños. Se trataba de fortalecer los vínculos familiares y reforzar su papel como primer grupo referencial de normas y valores a ser asimilados en su crecimiento. En consecuencia, la familia se constituía en el primer espacio natural de socialización. Desde esta perspectiva, los valores escolares y familiares debían corresponderse en la formación infantil. Otros aspectos apreciables en los relatos en Chanchito son la exaltación de la religión en la educación y la relación que existía entre los niños y los abuelos. Ellos eran quienes los recibían al llegar del colegio y se encargaban de enseñarles a orar, dar buenos consejos o contarles algún cuento.

El fragmento Evocación (Figura 5) hace énfasis en la emoción que la lectura genera en los niños y la forma cariñosa como la abuelita se relaciona con sus nietos. Este pasaje ejemplifica la manera en que el dispositivo opera (Figura 1): la práctica discursiva de la narración (lo que se dice, lo que se habla), produce una materialización de un rol ideal que proyecta una práctica no discursiva (acciones) reflejada en el comportamiento de un ciudadano que aún no existe (niño) todo permeado por el afecto (Jäger, 2003).

Las nuevas pedagogías, tanto de Ovidio Decroly como María Montessori, reconocían en los adultos que conforman la familia, un papel esencial en la educación de los niños. V. Caro apela a los padres, a los abuelos y las madres para que acompañen a los niños en diversas actividades que promuevan su conocimiento.

Si bien el partido conservador había aceptado ciertas tendencias liberales en su credo (Figueroa, 2019), las nuevas pedagogías, la relación Iglesia-Estado y el Estado confesional les resultaban temas sobre los que no se podía transigir ya que garantizaba, desde su perspectiva, la armonía, la unidad y el orden social.
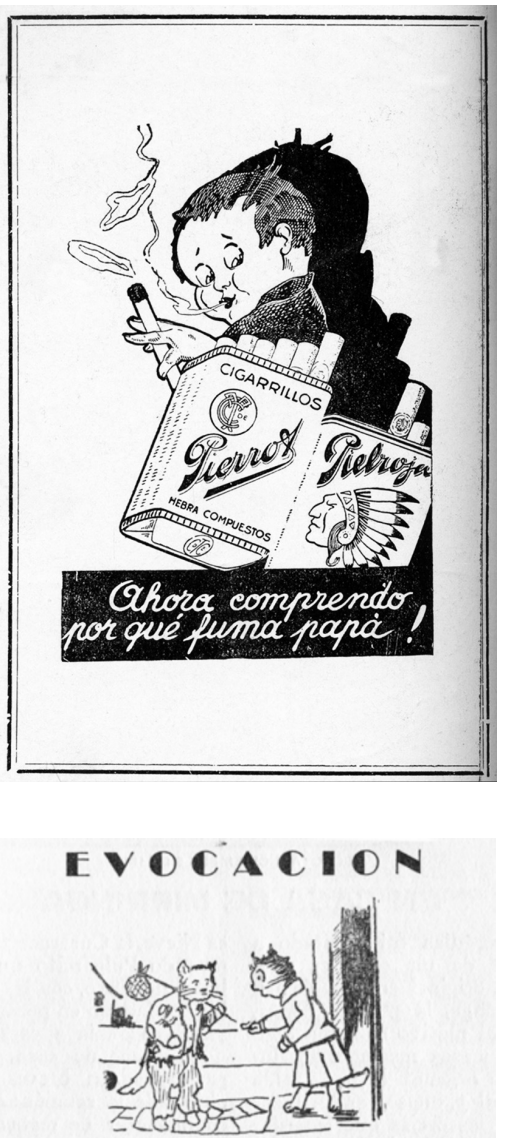

El pasado, la infancia: la abuelita relata A los nietos los cuentos que pidieron en coro, $\mathrm{Y}$ a la luz de la lámpara mis cabellos son oro, $\mathrm{Y}$ a la luz de la lámpara sus cabellos son plata.

Figura 3. Chanchito (1933), núm. 17 y 18, pág. 16

Figura 4. Aviso. Fuente: Chanchito, revista ilustrada para niños (1934, junio 7), II (42), pág. 24.

Figura 5. Evocación. Fuente: Chanchito (noviembre 9, 1933), I (19), pág. 4.

\section{La República liberal y la "Revolución en Marcha" (1934-1936)}

Si algo caracterizó el primer gobierno de Alfonso López (1934 y 1938) fue su intento por modernizar la nación e integrar a Colombia dentro del tiempo 
4. Civilización importada es un término usado por

Alfonso López que expresaba la necesidad de

traer a Colombia los mecanismos propios de los

Estados nación modernos y hacer del Estado un

guía del destino nacional con el fin de salir de la colonización extranjera y sus consecuencias de empobrecimiento nacional (López Pumarejo, 1935). 5. Secretario del Ministerio de Educación Nacional, jefe de su Sección de Publicaciones e ideólogo de Rin Rin (Trujillo M, archivo).

6. Comisión de cultura aldeana, grupo técnico compuesto por urbanistas, agrónomos, pedagogos y un relator literario quienes estudiaban la realidad del pueblo para facilitar al campesino su bienestar material y su dignidad (Díaz Soler, 2005). histórico internacional, en los mercados capitalistas y en la cultura moderna. Su lema la "Revolución en Marcha", consistía en una "revolución" sin sangre (López Pumarejo, 1935) que alterara el orden institucional y social colonialista y católico vigente en el territorio.

En el marco de la "Revolución en Marcha", la educación se puso al servicio de la transformación económica y cultural nacional, la cual debía desvincularse de las intenciones misericordiosas del catolicismo y convertirse en un instrumento no tradicionalista destinado a la tecnología y la ciencia con el fin de abrir nuevas fuentes de riqueza nacional. López consideraba que el régimen conservador había dejado un pobre legado educativo en las masas nacionales y asumió que su bajo nivel educativo era la principal causa del atraso nacional (Molano \& Vera, 1982).

Rin Rin estaba llamada entonces a modernizar la infancia rural que durante la Hegemonía Conservadora había sido instruida por el clero intransigente (Figueroa, 2019). Desde las aulas y el púlpito, entre otros, la Iglesia había promovido en la población campesina el autoritarismo, la tradición, la obediencia, la moral católica y la fe. Estos principios educativos no se adaptaban a la necesidad expresada por Alfonso López de activar la economía agropecuaria nacional con una triple finalidad: incorporar a las masas rurales en el proyecto nacional, aumentar los productos para la exportación y ampliar el consumo del mercado interno mediante el manejo elemental de una civilización importad $a^{4}$. De acuerdo al nuevo destino programado para la nación, integrar las masas rurales a la modernización fue el principal objetivo del gobierno de López, cuyos fines económicos, políticos, sociales y culturales estaban enfocados en eliminar los obstáculos entre modernidad y ruralidad. La escuela primaria debía convertirse en el medio de revolución para modernizar las tradicionales costumbres, aumentar la productividad mediante la tecnificación, crear mercados ágiles y mejorar las condiciones materiales y económicas de las clases populares (Sáenz, Saldarriaga, \& Ospina, 1997).

Al introducir reformas a la Constitución de 1936, el gobierno de López se proponía otorgarle al Estado la dirección de la educación nacional y anular los poderes de la Iglesia adquiridos bajo la Constitución de 1886 y el Concordato de 1887. La Ley 32 de 1936 obligaba a los centros educativos a recibir estudiantes sin distinción de nacimiento, de clase, de raza y de religión. El artículo 14 de 1936 eliminaba el privilegio eclesiástico de organización y dirección educativa y el Decreto 620 daba libertad de enseñanza respecto a doctrinas religiosas, morales, científicas, filosóficas y políticas (Molano \& Vera, 1982). Esta reforma estuvo directamente influida por la Revolución bolchevique y la mexicana (Cajas, 2018).

\section{Estado como educador de la infancia rural}

Durante el primer mandato de López, el Estado se convirtió en el guía y velador de la educación popular; de manera paternalista quiso llevar de la mano a las masas rurales hacia las mínimas formas de vida civilizada (Silva, 2006). Jorge Zalamea ${ }^{5}$, tras su experiencia como relator de las investigaciones del Departamento de Nariño ${ }^{6}$, argumentó la imposibilidad de las familias campesinas de ocuparse de la educación de sus hijos por la falta de recursos materiales e instructivos. Esta decisión gubernamental incorporaba una visión propia de la modernidad europea que hizo del Estado el educador por excelencia (Herrera, 2013). Consecuente con los principios intervencionistas del gobierno de López, 

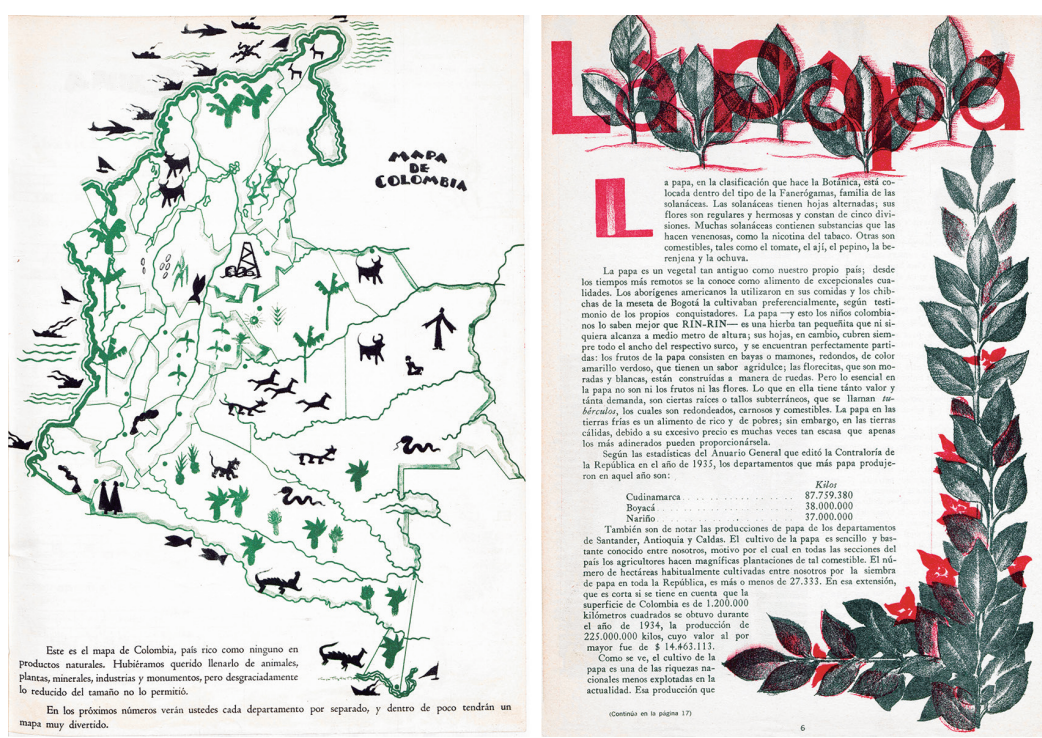

Jorge Zalamea propuso el programa educativo rural como un repertorio de soluciones que atacaran los problemas de miseria material y espiritual de las masas populares. Darío Echandía, ministro de Educación Nacional, supo expresar en sus memorias el compromiso estatal:

El Estado no puede ofrecer por el momento a esas masas auxilio intelectual y espiritual distinto al que se daría de los cuatro años de la escuela primaria, está en el deber de hacer de ellos una etapa de preparación intensa que permita al ciudadano defenderse con las mejores armas posibles de las contingencias adversas que le esperan en lo físico, en lo moral, en lo económico y en lo social. (Echandía, 1936, p. 43)

Para la transformación de las masas rurales, el Estado solo tenía esos cuatro años de escuela primaria pública obligatoria, tiempo en el que debía resolver el problema más grave del país: darle a conocer al niño su propia tierra en tal forma que espontáneamente la amara, conscientemente la respetara, prácticamente la utilizara e intelectualmente la entendiera en su enorme diversidad de aspectos (Echandía, 1936). En la Figura 6 se puede observar cómo Rin Rin exponía las riquezas naturales a ser explotadas.

Rin Rin contenía la nacionalización de la educación primaria, por lo que el material escolar se nutría de motivos y temas locales. Conforme al interés nacionalista y nacionalizador en el que la modernización se apoyó, en la enseñanza de la escuela primaria y en las páginas de Rin Rin todo giró en torno al gran centro de interés que era Colombia (Echandía, 1936). En la Figura 6 se muestra el mapa de Colombia como destino nacional que alberga las potenciales riquezas a ser explotadas. De esta manera, Herrera (1994) señala: "se evidencian las intenciones estatales en hacer del capital cultura y del capital educativo una conversión en capital" (p.g).

Las páginas de Rin Rin hablaban del algodón, del cacao, de las altiplanicies, del maíz y de la papa (Figura 6), con ello se pretendía adecuar la educación a las
Figura 6. Rin Rin (1936), núm. 1, Mapa de Colombia. Rin Rin (1937), núm. 10, La papa. 
Figura 7. Rin Rin (1936), núm. 5. Pastorcita.

7. La noción de "libertad" en el pensamiento liberal se presentó relacionado con intenciones instrumentales ideológicas y económicas.

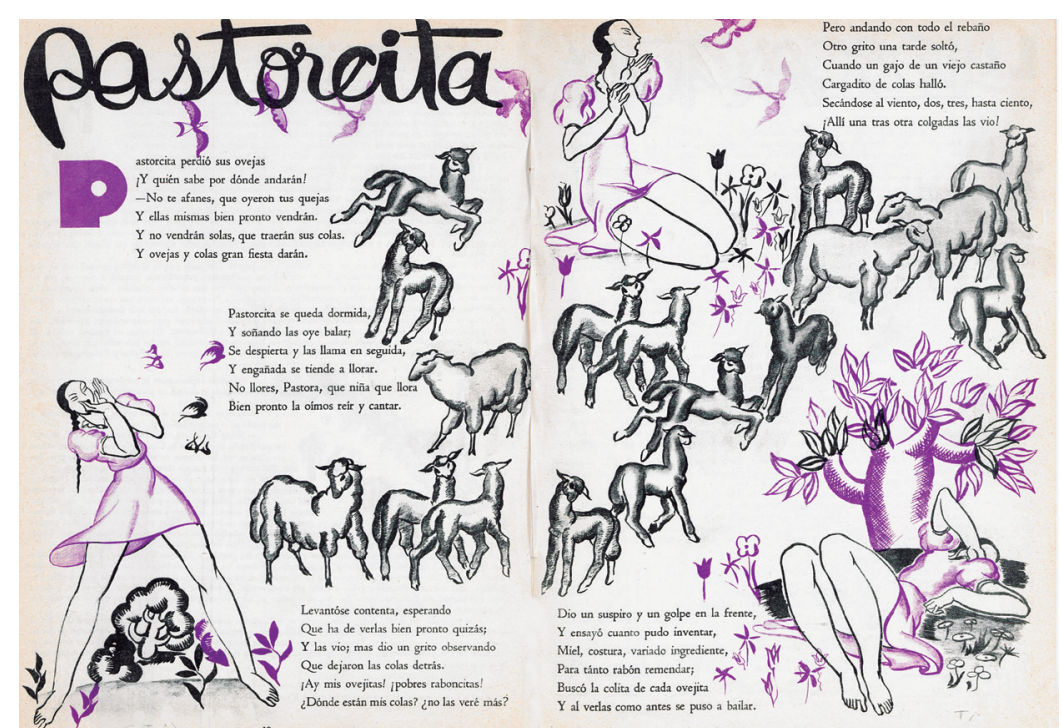

"condiciones físicas, económicas y sociales de Colombia" (López Bermúdez, 2014, p. 114). Los niños campesinos, en los cuatro años obligatorios escolares, debían aprender en libros o cuadernos que hablaran de la diversidad de las regiones, conocer los números para la resolución de sus intereses familiares, así como introducirse en "los comienzos de las ciencias naturales sobre las plantas y las bestias que los rodean" (Echandía, 1936, p. 41).

Con Rin Rin se quería asegurar la permanencia de la población rural en el campo y evitar su desplazamiento hacia las ciudades y, al mismo tiempo, ampliar la producción agropecuaria para el consumo interno y para la exportación. En la Figura 7 pareciera que la pastorcita experimenta un inmenso placer en sus actividades rurales. La intención no era otra que sublimar el paisaje, sus personajes y las acciones realizadas, mostrar prosperidad y belleza en el ánimo de movilizar el sentimiento popular de arraigo y promover su productividad.

\section{La "libertad" infantil en Rin Rin y El país de Lilac}

Compartían Rin Rin y El país de Lilac el interés del Estado de fortalecer un espíritu activo y dinámico propio de la modernidad productiva. El cuento de El país de Lilac es una apología reivindicativa en pro de la libertad de los niños tan mermada en las escuelas religiosas donde la obediencia y el miedo eran instrumentos educativos. La "libertad" " del sujeto moderno conllevaría hacia el futuro un ciudadano emprendedor con capacidad de autogobierno.

En el fragmento que sigue, también se exalta el valor experiencial didáctico propuesto por la Escuela Activa:

Hay un país semejante al de Liliput que visitó Gulliver: es el país de Lilac. Allí los niños viven solos, se gobiernan a sí mismos y han prescindido completamente de las personas grandes. Todo es tan diferente en el país de Lilac, que en las vitrinas de los almacenes dicen: "Ver y tocar". (Díaz Díaz, 1938, p. 3)

Durante el gobierno de López Pumarejo queda claro que las pautas para la educación infantil se expresan tanto en Rin Rin como en El país de Lilac; en 

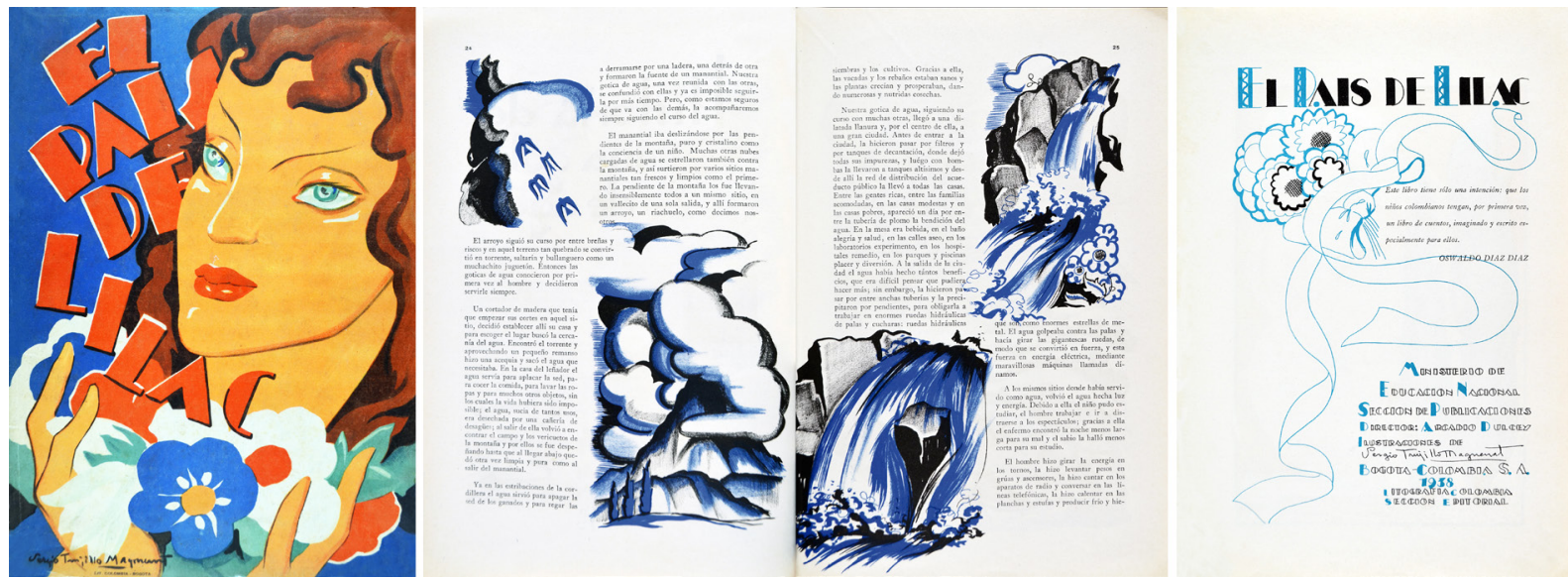

ellas se cuida de hacer del niño un adulto pequeño, y se desestima infantilizarlo mediante imágenes grotescas de lazos, osos de peluche y florecillas cursis. De otro lado, el estilo de las ilustraciones y tipografías dan cuenta de un rigor que, si bien se dirige a un pequeño lector, lo sabe con capacidad de entendimiento e inteligencia, condiciones que preparan al individuo para la construcción de un futuro ciudadano moderno racional, dinámico y con capacidad de autogobernarse (Figura 8).

\section{Conclusiones}

Aunque el Estado le arrebató la educación infantil a la Iglesia y a las familias campesinas para llevar a las masas hacia la modernización durante la "Revolución en Marcha” y alcanzar la emancipación económica y cultural de la nación, el ministro Echandía aclaraba que los cambios educativos no buscaban alterar las prerrogativas espirituales de la Iglesia, que la escuela liberal solo quería inspirarse en la moral cristiana (Echandía, 1936). Sin embargo, la Reforma Constitucional de 1936 fue interpretada por la institución eclesiástica como el derrumbe de valores sagrados. Por ello, se entiende que el partido conservador junto con la comunidad eclesiástica se tornara más intransigente frente a las reformas liberales. No se aceptaba la disolución del vínculo Estado-Iglesia y pérdida del control sobre la educación.

Rin Rin y El país de Lilac, en el contexto histórico, pretendieron romper el orden social al tratar de influir en la formación de la ciudadanía infantil en contravía de lo que Chanchito proponía sobre el futuro ciudadano colombiano católico, obediente, productivo, preservador de los valores y roles familiares tradicionales. Las publicaciones liberales se interesaron en promover la formación de un ciudadano rural moderno, consumidor y ahorrador destinado a cumplir su función como sujeto histórico y aportar a la modernización nacional. Igualmente, fomentaron la tecnificación, el amor y conocimiento del territorio nacional, el laicismo y el autogobierno basado en la "libertad". No obstante, las ideologías de las publicaciones liberales se introducían en un marco contextual gobernado por las mentalidades que Chanchito sustentaba; fueron precisamente estas resistencias culturales, entre otros factores, las que incidieron en el poco impacto educativo que tuvo la "Revolución en Marcha". 


\section{Referencias}

Arias, R. (2003). El episcopado en Colombia: intransigencia y laicidad 1850 - 2000. Bogotá: Universidad de los Andes.

Cajas Sarria, M. (2013). "Alfonso López Pumarejo y la última Corte Suprema de Justicia de la hegemonía conservadora, 1934-1935". Revista de Derecho. Universidad del Norte. N4O. ISSN: 2145-9355 (online), 98 - 135.

Cajas Sarria, M. (2018). "Haciendo memoria de una Corte que le temía a la revolución: a propósito de un juicio de constitucionalidad a la represión bajo la hegemonía conservadora". Revista de Derecho N 49, Barranquilla. ISSN: 2145-9355 (online), 318 - 351.

Cajas Sarria, M. (Marzo de 2019). Historia Constitucional (ISSN1576-472). N 19, 2018, págs. 505-532. Recuperado de http://www.historiaconstitucional.com

Caro, V. (1933 - 1934). Chanchito números 1 al 63. Bogotá.

Diario Oficial de la Nación No. 12,122. (jueves 14 de julio de 1904). Bogotá: Imprenta Nacional.

Díaz Díaz, O. (1938). El país de Lilac. Bogotá: Ministerio de Educación Nacional.

Díaz Soler, C. (2005). El pueblo de sujeto dado a sujeto político por construir: el caso de la campaña de Cultura aldeana en Colombia (1934-1936). Bogotá: Universidad Pedagógica Nacional.

Echandía, D. (1936). Memorias que el Ministro de Educación Nacional presenta al congreso en sus sesiones de 1936. Informe sobre enseñanza secundaria. Recuperado de goo.gl/vFM7S6

Figueroa Salamanca, H. (marzo de 2019). Monseñor Miguel Ángel Builes, un político intransigente y escatológico (1925 - 1950). Recuperado de Anuario de Historia regional y de las fronteras, 21 (1), pp. 237 - 259: http:// eds.a.ebscohost.com.ezproxy.utadeo.edu.co:2048/ eds/pdfviewer/pdfviewer?vid=2\&sid

Herrera, M. (1994). Los intelectuales y el despertar cultural del siglo, el caso de la Escuela Normal Superior, una historia reciente y olvidada. Bogotá: Universidad Pedagógica Nacional.

Herrera, M. (Marzo de 2019). Historia de la educación en Colombia. La República Liberal y la Modernización de la Educación: 1930 - 1943. Recuperado de Revista Colombiana de Educación: https://doi. org/10.17227/01203916.5297

Jäger, S. (2003). "Discursos y conocimiento: aspectos teóricos y metodológicos de la crítica del discurso y del análisis del dispositivo". En Métodos del análisis crítico del discurso (págs. 61 - 99). Barcelona: Gedisa.
Londoño Vega, P. (2005). "Cartillas y manuales de urbanidad y del buen tono, catecismo cívicos y prácticos para un amable vivir". Credencial Historia, 85 .

López Bermúdez, A. (2014). Jorge Zalamea, enlace de dos mundos. Quehacer literario y cosmopolitismo (1905 1969). Bogotá: Universidad del Rosario.

López de Mesa, L. (1935). Gestión administrativa y perspectiva del Ministerio de Educación. Recuperado de goo.gl/vFM7S6content_copyCopy short URL

López Pumarejo, A. (1935). La política oficial. mensajes presidenciales y discursos del presidente López. Tomo II. Bogotá: Imprenta Nacional.

Molano, A., \& Vera, C. (1982). Evolución de la política educativa en el siglo XX. Bogotá: Universidad Pedagógica Nacional.

Ospina Canencio, C. (enero - junio de 2017). Lectores imaginados por las revistas infantiles: Chanchito revista semanal ilustrada para niños y Mamita revista semanal de cuentos infantiles. Recuperado de Revista de Humanidades (online): http://www.redalyc.org/ articulo.oa?id=321249925005> ISSN 0717-0491

Sáenz, J., Saldarriaga, Ó., \& Ospina, A. (1997). Mirar la infancia: pedagogía, moral y modernidad en Colombia, 1903 - 1946. Volúmen 2. Medellín: Universidad de Antioquia.

Silva, R. (2006). Sociedades campesinas, transición social y cambio cultural en Colombia: la Encuesta Folclórica Nacional de 1942: aproximaciones analíticas y empíricas. Medellín: La Carreta Editores.

Tirado Mejía, Á. (1995). Aspectos políticos del primer gobierno de Alfonso López Pumarejo (1934 - 1938). Bogotá: Planeta.

Trujillo Acosta, M., \& Peters Rada, V. (enero - junio de 2018). Rin Rin. Revista Infantil del Ministerio y Chanchito. Revista llustrada para Niños. La dimensión de sus imágenes. Dos revistas de ideologías contrarias publicadas durante la década de los treinta en Colombia. Recuperado de Análisis: https://revistas.usantotomas. edu.co/index.php/analisis/article/view/3710

Trujillo Magnenat, S. (1936 - 1939). Rin Rin. Bogotá, Colombia: Ministerio de Educación Nacional. Sección de Publicaciones.

Trujillo Magnenat, S. (s.f.). Archivo documental y gráfico dejado a sus herederos Trujillo Dávila. Colombia.

Zalamea, J. (8 de enero de 1978). "Departamento de Nariño: esquema para una interpretación sociológica, 1936". En Literatuta, política y arte (págs. 59 - 107). Bogotá, Colombia: Instituto Colombiano de Cultura. 